\title{
Risk Factors Associated with Thyroid Carcinoma in North Pakistan
}

\author{
Muhammad Aleem Khan ${ }^{1 *}$, Kamran Hakeem Khan², Sajid Ali Shah' ${ }^{2}$ Kahkashan \\ Ali Mir ${ }^{1}$, Mubarik Khattak ${ }^{2}$, Muhammad Faheem Shahzad ${ }^{1}$
}

\begin{abstract}
Background: Epidemiological data on thyroid cancer and associated risk factors are scarce in our setting. The present study was therefore designed to gather data which could be helpful in providing insights to thyroid physicians and surgeons for better management of affected patients. Purpose: To determine the frequency of carcinoma thyroid among patients presenting with goiter and its association with TSH, Tg/ATg and other demographic factors. Materials and Methods: A total of 73 adult patients of either gender with solitary solid cold nodules and/or multi-ndoular goiter (MNG) with predominant solid cold nodules were enrolled. All surgically resected samples were sent for histopathology. The frequency of thyroid cancer and its subtypes was noted and tested for association with gender, age ( $<$ or $\geq 40$ years), recent increase in swelling size, TSH, Tg and ATg. Results: Thyroid cancer was diagnosed in $26 \%(n=19)$ of the patients, $14(73.7 \%)$ being diagnosed with papillary thyroid cancer and $5(\mathbf{2 6 . 3 \%})$ with follicular thyroid cancer. No other subtypes were noted. Presence of thyroid cancer was significantly associated with recent increase in swelling size and higher TSH Values mean TSH values $(\mathrm{P}<0.05)$. No significant association was found with gender, age, Tg and ATg values $(\mathrm{P}>0.05)$. Conclusions: Overall percentage of thyroid cancer in our study sample was found to be $26 \%$, with a predominance of papillary over follicular lesions. Rates were significantly higher in patients who had history of recent increase in swelling size and higher and higher pre-surgery TSH values.
\end{abstract}

Keywords: Thyroid cancer - goiter - thyroid nodules - TSH

Asian Pac J Cancer Prev, 17 (1), 377-380

\section{Introduction}

Thyroid carcinoma is a relatively rare tumor, but it represents the most frequent form of cancer of the endocrine glands. It accounts for $1 \%$ of all human neoplasias and globally its annual incidence is estimated to be 0.5 to 10 per 100,000 subjects in the world population (Dong et al., 2013). The peak incidence is in the third and fourth decade of life (Morris et al., 2013). Worldwide incidence rates of thyroid cancers vary widely, with the causes potentially related to inherent racial or ethnic differences, geographical or environmental differences including iodine excess or deficiency and possible radiation exposure (Bukhari et al., 2013). Majority of patients with thyroid carcinoma present with nodular goiters with the frequency of malignancy being $3 \%$ among multi-nodular goiters and $4.4 \%$ among solitary nodule (Moosa et al., 2007). In Pakistan the most common thyroid malignancy is papillary carcinoma (Iftikhar et al., 2011). Patients usually presents with swelling in the neck which may have recently increased in size, small lumps in other areas of neck, hoarseness of voice and difficulty in breathing and swallowing (in case of larger swelling size). Clinical examination of the gland may also provide clues for a suspected malignancy like a hard lump, palpable lymph nodes, a positive berry's sign and immobile vocal cords on indirect laryngoscopy (Afolabi et al., 2010; Soomro et al., 2011).

Internationally there is growing awareness about the significant consequences of thyroid carcinoma. On national level we need mass awareness and to foster knowledge about this cancer as the prognosis is excellent after surgery and radioactive iodine treatment. The epidemiological data on thyroid cancer and its associated risk factors was scarce in our settings. Present study was designed to gather the data in our settings which could be helpful in providing insights to the thyroid physicians and surgeons who are primarily dealing with these patients. Our objective was to determine the frequency of carcinoma thyroid among patients presenting with goiter and its association with TSH, Tg/ATg and other demographic factors in our settings.

\section{Materials and Methods}

${ }^{I}$ Nuclear Medicine Department, Nuclear Medicine, Oncology and Radiotherapy Institute, ${ }^{2}$ Department of General Surgery, Pakistan Institute of Medical Sciences, Islamabad,Pakistan*For correspondence:draleemkhan@yahoo.com 
It was a cross sectional study and was carried out at Department of Surgery, Pakistan Institute of Medical Sciences (PIMS), a tertiary care hospital in Islamabad, during January 2014 to December 2014. The study was approved by hospital ethical committee. All the patients who presented for thyroid surgery during this period were assessed with adequate history, thorough clinical examination and necessary investigations where needed (Thyroid Function Tests [TFT's], thyroid scintigraphy, ultrasound neck, serum thyroglobulin $[\mathrm{Tg}]$ and antithyroglobulin antibodies [ATg]). Patients who presented with diffuse toxic goiter, pure cystic nodules and autonomously hyper-functioning thyroid nodule were excluded from study. Patients who already underwent any thyroid surgery were also excluded. Patients who had solitary solid cold nodule and MNG with predominant solid cold nodule were selected for further analysis. A fully informed, understood and voluntarily written consents was taken from all the patients. The operative procedures were undertaken under general anesthesia. The procedure was tailored according to the presumptive pre-operative diagnosis. The entire resected surgical specimen was subjected to histopathology examination to establish final diagnosis of the thyroid disorder. The frequency and percentage of thyroid cancer and its subtypes was noted and tested for association with gender, age $(<40,>40$ years) and recent increase in swelling size by employing chi-square test. Continuous variables like TSH, Tg and ATg were tested for association by employing independent t-test. A P-value of less than 0.05 was considered as statistically significant.

\section{Results}

A total of one hundred and eighty one $(n=181)$ patients irrespective of gender with goiter presented to the surgery department during the study period. One hundred and eight $(n=108)$ patients were excluded from the study. Out of those, fifty three $(n=53)$ patients presented with diffuse toxic goiter (confirmed on thyroid function tests and thyroid scintigraphy), twenty six $(n=26)$ patients presented with pure cystic nodules (confirmed on ultrasound neck), eighteen $(n=18)$ patients presented with autonomously hyper-functioning thyroid nodule (confirmed on thyroid function tests and thyroid scintigraphy) and eleven $(n=11)$ patients had history of previous thyroid surgery and presented with regenerated nodules (confirmed on history and clinical examination). Seventy three $(n=73)$ patients fulfilled the recruitment criteria and were further analyzed. Demographic characteristics of study population are presented in (table 1). There were $56.2 \%(n=41)$ of

Table 1. Demographic Profile of the study Population

\begin{tabular}{lcc}
\hline & $\begin{array}{c}\text { Number } \\
\text { (percentage) }\end{array}$ & $\begin{array}{c}\text { Mean Age } \pm \text { SD } \\
\text { (years) }\end{array}$ \\
\hline Male & $19(26 \%)$ & $36.95 \pm 12.2$ \\
Females & $54(74 \%)$ & $39.1 \pm 12.3$ \\
\hline Total & $73(100 \%)$ & $38.5 \pm 12.25$ \\
\hline
\end{tabular}

Table 2. Association with Gender, age and Recent Increase in Swelling size

\begin{tabular}{|c|c|c|c|}
\hline \multirow[t]{2}{*}{ Variables } & \multicolumn{2}{|c|}{ Thyroid Cancer } & \multirow{2}{*}{$\begin{array}{c}\text { P-Value } \\
\text { Chi-Square } \\
\text { Test }\end{array}$} \\
\hline & Present & Absent & \\
\hline \multicolumn{4}{|l|}{ Gender } \\
\hline Males & $\begin{array}{c}7 \\
36.80 \%\end{array}$ & $\begin{array}{l}12 \\
22.20 \%\end{array}$ & 0.212 \\
\hline Females & $\begin{array}{l}12 \\
63.20 \%\end{array}$ & $\begin{array}{l}42 \\
77.80 \%\end{array}$ & \\
\hline \multicolumn{4}{|l|}{ Age } \\
\hline$<40$ Years & $\begin{array}{l}12 \\
63.20 \%\end{array}$ & $\begin{array}{l}29 \\
53.70 \%\end{array}$ & 0.475 \\
\hline$>40$ Years & $\begin{array}{c}7 \\
36.80 \%\end{array}$ & $\begin{array}{l}25 \\
46.30 \%\end{array}$ & \\
\hline \multicolumn{4}{|c|}{ Recent Increase In Swelling Size } \\
\hline Present & $\begin{array}{c}9 \\
47.40 \%\end{array}$ & $\begin{array}{l}12 \\
22.20 \%\end{array}$ & 0.037 \\
\hline Absent & $\begin{array}{l}10 \\
52.60 \%\end{array}$ & $\begin{array}{l}42 \\
77.80 \%\end{array}$ & \\
\hline
\end{tabular}

Table 3. Association with TSH, TG and ATG

\begin{tabular}{lccc}
\hline Variables & \multicolumn{2}{c}{ Thyroid Cancer } & \multirow{2}{*}{$\begin{array}{c}\text { P- Value } \\
\text { (T-Test) }\end{array}$} \\
\cline { 2 - 3 } & Present & Absent & \\
\hline TSH (IU/ml) & $4.76 \pm$ & $2.48 \pm$ & 0.00 \\
Mean \pm Sd (ng/ml) & 2.43 & 1.65 & \\
Tg (ATg (IU/ml) & $310.7 \pm$ & $353.6 \pm$ & 0.74 \\
& 546.9 & 450.5 & \\
Atg (Iu/Ml) & $304.8 \pm$ & $183.4 \pm$ & 0.161 \\
& 326.4 & 319.4 & \\
\hline
\end{tabular}

patients who were less than 40 years of age and $43.8 \%$ $(n=32)$ were greater than 40 years of age. Thyroid cancer was diagnosed in $26 \%(n=19)$ of patients. In patients with thyroid cancer $(n=19), 73.7 \%(n=14)$ were diagnosed as papillary thyroid cancer and $26.3 \%(n=5)$ were diagnosed as follicular thyroid cancer. No other subtypes noted in our results. Presence of thyroid cancer was significantly associated with recent increase in swelling size and higher mean TSH values $(\mathrm{P}<0.05)$. No significant association was found with gender, age, Tg and ATg values $(\mathrm{P}>0.05)$. Results are tabulated in table 2 and 3.

\section{Discussion}

Thyroid nodules are extremely common. In our overall study sample, thyroid cancer was found in $26 \%(\mathrm{n}=19)$ of patients. In patients with thyroid cancer $(n=19), 73.7 \%$ $(n=14)$ were diagnosed with papillary thyroid cancer and $26.3 \%(n=5)$ were diagnosed with follicular thyroid cancer. No other subtypes noted in our results. In one of the largest most recent and single center study conducted at Department of Pathology, Holy Family Hospital, Rawalpindi, Pakistan, Qureshi et al, found the percentage of neoplastic lesions as $18 \%$ (versus $26.3 \%$ in our study) (Qureshi et al., 2015). The difference may be attributed to different inclusion criteria. In another recent study conducted at department of Pathology, Taibah University, Madinah, Saudi Arabia, Albasri A, et al, found 27.7\% 
cases were neoplastic (Albasri et al., 2014). Two other reports based on large population based studies probably provide a best accurate estimate of the true frequency of thyroid cancer among patients with thyroid nodules. In a community hospital in North Carolina where most patients with nodules were referred for surgery without benefit of biopsy, 6.5 percent of excised nodules were cancers (Werk et al., 1984). In Catania, Italy, 2327 patients presenting with nodules were evaluated by fine needle aspiration biopsy, and 391 were selected for surgery (Belfiore et al., 1989). Cancers were found in 28 percent of the surgical specimens, which represented only 5 percent of all nodules. However, in Boston, among patients referred to a thyroid practice, the rate of malignancy in thyroid nodules was 14 percent (Frates et al., 2006). In our settings, usually surgery is decided on FNAC results for patients showing suspicion for malignancy and malignant category. This could be the likely reason of higher frequency of thyroid cancer in our study as compared to North Carolina study (6\% versus $26 \%$ in our study) where FNAC results were not accounted for the selection for surgery. We also excluded all the patients with pure cystic nodules on ultrasound, although, they appeared cold on thyroid scintigraphy. This may also result in higher frequency of thyroid cancer in our study sample as chances of thyroid cancer in pure cystic nodules are very rare. However, our study results are comparable with the Italian study (28\% versus $26 \%$ in our study) as they had the similar selection criteria. Differentiated thyroid cancers (papillary and follicular) accounts for about 90 percent of all thyroid cancers, usually have a good prognosis (Sisson, 1989). Due to relatively smaller sample size for this kind of epedimiological study, all thyroid cancers in our study came out to be papillary and follicular thyroid cancer $(100 \%)$. Less frequent thyroid cancers (medullary, anaplastic and lymphoma) did not show up in our study due to this relatively smaller sample size.

A study conducted by Mortensen et al. (1955) showed that thyroid nodularity increases with age (Mortensen et al., 1955). However, no such association was found in present study. The presence of a thyroid nodule in a child is twice more likely to be a cancer than if it was in an adult (Belfiore et al., 1989). Among patients with thyroid nodules, the rate of cancer is twice as high in men as women ( 8 versus 4 percent). We did not include children in our study and our study results showed no significant difference in males and females. This could again due to smaller sample size. Other studies showed that frequency of thyroid cancer is higher in adults over age 60 and under age 30 years than in those aged 30 to 60 years (Belfiore et al., 1992). Although the difference was also not statistically significant in different age groups in our study but one can see the higher percentages in younger age group. Again due to smaller sample size the difference could not be appeared to be statistically significant. Association with a history of recent increase in swelling size was significant in our study. Other studies showed that thyroid cancer appears to be more common in nodules $\geq 2 \mathrm{~cm}$ compared with $<2 \mathrm{~cm}$ and associated with recent increase in swelling size. In one study of 4955 patients, the risk of malignancy in nodules 1.0 to $1.9 \mathrm{~cm}$ was 10.5 percent, while the risk in nodules 2.0 to $2.9,3.0$ to 3.9 , or greater than $4 \mathrm{~cm}$ was 14,16 , and 15 percent, respectively (Kamran et al., 2013). While larger nodule size over $2 \mathrm{~cm}$ was not associated with an increased risk of malignancy, the proportion of papillary cancers reduced from 92 to 74 percent, while the proportion of follicular cancers increased from 6 to 16 percent as nodules increased from under 2 to over $4 \mathrm{~cm}$.

Preoperative higher TSH values showed significant association with thyroid cancer in the present study. Other studies showed similar results and serum TSH is considered as an independent risk factor for predicting malignancy in a thyroid nodule. In a study of 1500 patients presenting to a thyroid practice, the prevalence of malignancy was $2.8,3.7,8.3,12.3$, and 29.7 percent for patients with serum TSH concentrations $<0.4 \mathrm{mU} / \mathrm{L}$, 0.4 to $0.9 \mathrm{mU} / \mathrm{L}, 1.0$ to $1.7 \mathrm{mU} / \mathrm{L}, 1.8$ to $5.5 \mathrm{mU} / \mathrm{L}$, and $>5.5 \mathrm{mU} / \mathrm{L}$, respectively (Boelaert et al., 2006). Other studies have shown that when cancer was diagnosed, a higher TSH was associated with a more advanced stage of cancer (Haymart et al., 2008; McLeod et al., 2014). We suggest further studies in our settings with different cut-off values and using receiver operative curve analysis in larger sample size.

No significant association was found with preoperative Tg and ATg values in the present study. Higher standard deviation values measures in our studies for Tg and ATg are quite evident and may be due to the fact that we did not have the Tg/ATg measurements from the same laboratory and we had a very limited capacity to rule out lab to lab variation of these results. Other studies showed that despite a trend toward assay standardization, serum Tg values obtained with different assays cannot be directly compared, as interassay variability remains substantial (Weightman et al., 2003). Serum Tg and ATg levels can be elevated in many thyroid diseases. An elevated level does not help discriminate benign from malignant thyroid nodules. Thus, Tg and ATg are usually not measured as part of the evaluation of patients with a thyroid nodule. However, they have a definite role in long term monitoring of thyroid cancer patients after surgery and radio-iodine ablation (Schlumberger et al., 2007).

Limitations of current study: $i$ ). We excluded all the patients with pure cystic nodules on ultrasound, although, they appeared cold on thyroid scintigraphy. This might resulted in higher frequency of thyroid cancer in our study sample as chances of thyroid cancer in pure cystic nodules are very rare, $i i)$. Due to relatively smaller sample size for this kind of epidemiological study, all thyroid cancers in our study came out to be papillary and follicular thyroid cancer. Less frequent thyroid cancers (medullary, anaplastic and lymphoma) did not show up in our study, iii). A further potential limitation is that we did not have the $\mathrm{Tg} / \mathrm{ATg}$ measurements from the same laboratory and we had a very limited capacity to rule out lab to lab variation of these results.

Overall percentage of thyroid cancer in our study sample was found to be $26 \%(\mathrm{n}=19$; papillary 14 , follicular 5 ) which was significantly higher in patients who had history of recent increase in swelling size and higher presurgery TSH values. 


\section{Acknowledgements}

We would like to acknowledge all the studied patients for their cooperation. We wish to pay special gratitude to Dr. Rakhshanda Rashid, consultant surgeon department of surgery PIMS, Islamabad and Dr. Javaid Irfan, Director NORI for their support and encouragement throughout the project. We also acknowledge our families and friends for their continuous support and motivation.

\section{References}

Afolabi AO, Oluwasola AO, Akute OO, Akang EE, Ogundiran TO, Ogunbiyi JO (2010). Review of fine needle aspiration cytology in the management of goitres in Ibadan, Nigeria. Niger J Clin Pract, 13, 163-6.

Albasri A, Sawaf Z, Hussainy AS, Alhujaily A (2014). Histopathological patterns of thyroid disease in Al-Madinah region of Saudi Arabia. Asian Pac J Cancer Prev, 15, 5565-70.

Belfiore A, La Rosa GL, La Porta GA (1992). Cancer risk in patients with cold thyroid nodules: relevance of iodine intake, sex, age, and multinodularity. Am J Med, 93, 363-4.

Belfiore A, Giuffrida D, La Rosa GL (1989). High frequency of cancer in cold thyroid nodules occurring at young age. Acta Endocrinol (Copenh), 121, 197-9.

Boelaert K, Horacek J, Holder RL (2006). Serum thyrotropin concentration as a novel predictor of malignancy in thyroid nodules investigated by fine-needle aspiration. J Clin Endocrinol Metab, 91, 4295-7.

Bukhari S, Sadiq S, Memon J, Baig F (2009). Thyroid Carcinoma in Pakistan : a retrospective review of 998 cases from an academic referral centre. Hematol Oncol Stem Cell, 2, 345-8.

Dong W, Zhang H, Li X, Hel Wang Z (2013). The changing incidence of thyroid cancer in Shenyang, China before and after universal salt iodization. Med Sci Monit, 19, 49-53.

Frates MC, Benson CB, Doubilet PM (2006). Prevalence and distribution of carcinoma in patients with solitary and multiple thyroid nodules on sonography. J Clin Endocrinol Metab, 91, 3411-3.

Haymart MR, Repplinger DJ, Leverson GE (2008). Higher serum thyroid stimulating hormone level in thyroid nodule patients is associated with greater risks of differentiated thyroid cancer and advanced tumor stage. JClin Endocrinol Metab, 93, 809-12.

Iftikhar A, Naseeb AK, Khwaja A, et al (2011). Patterns of differentiated thyroid cancer in Balochistan province of Pakistan: Some initial observations. Med J Malaysia, 66, 322-5.

Kamran SC, Marqusee E, Kim MI (2013). Thyroid nodule size and prediction of cancer. J Clin Endocrinol Metab, 98, 564-5.

McLeod DS, Cooper DS, Ladenson PW (2014). Prognosis of differentiated thyroid cancer in relation to serum thyrotropin and thyroglobulin antibody status at time of diagnosis. Thyroid, 24, 35-6.

Moosa SA, Junaid M, Khan FW, Afzal Y, Sultan N (2007). Prevalence of malignancy in resected specimens of patients operated for benign nodular goiter. Pak J Surg, 23, 29-32.

Morris LG, Sikora AG, Tosteson TD, Davies L (2013). The increasing incidence of thyroid cancer: the influence of access to care. Thyroid, 23, 885-91.

Mortensen JD, Woolner LB, Bennett WA (1955). Gross and microscopic findings in clinically normal thyroid glands. $J$ Clin Endocrinol Metab, 15, 1270-2.

Qureshi IA, Khabaz MN, Baig M, et al (2015). Histopathological findings in goiter: A review of 624 thyroidectomies. Neuro
Endocrinol Lett, 36, 48-52.

Schlumberger M, Hitzel A, Toubert ME (2007). Comparison of seven serum thyroglobulin assays in the follow-up of papillary and follicular thyroid cancer patients. J Clin Endocrinol Metab, 92, 2487-91.

Sisson JC (1989). Medical treatment of benign and malignant thyroid tumors. Endocrinol Metab Clin North Am, 18, 359-63.

Soomro SA, Memon MR, Abro H, Mahar M (2011). Frequency of malignancy in cold nodule thyroid. Med channel, 17,44-9.

Weightman DR, Mallick UK, Fenwick JD, Perros P (2003). Discordant serum thyroglobulin results generated by two classes of assay in patients with thyroid carcinoma: correlation with clinical outcome after 3 years of follow-up. Cancer, 98, 41-5.

Werk EE, Vernon BM, Gonzalez JJ (1984). Cancer in thyroid nodules. A community hospital survey. Arch Intern Med, 144, 474-5. 